IKONOMIKA: Journal of Islamic Economics and Business

Volume 2, No 2 (2017)

ISSN: 2527-3434 (PRINT) - ISSN: 2527-5I43 (ONLINE)

Page: 20I - 212

\title{
DETERMINAN PENGGUNANAAN REKENING BANK SYARIAH PADA PENGELOLA MASJID DI DKI JAKARTA
}

\author{
Faozan Amar' ${ }^{1}$ Edi Setiawan ${ }^{2}$ \\ Universitas Muhammadiyah Prof. DR. HAMKA \\ zanamar@yahoo.com ${ }^{1}$, edisetiawan@uhamka.ac.id ${ }^{2}$
}

\begin{abstract}
This research is a quantitative research using analytical descriptive method. In this case, by describing Determination Analysis of Understanding of Sharia Bank Account Selection to Mosque Management in DKI Jakarta. The low understanding of takmir mosque management will understand the product of syariah bank let alone the benefit of syariah bank account for the people's economy. For that sharia banking should continue to socialize more intensively again through the more popular media in the management of Takmir Masjid. The results concluded that the ownership of accounts in Islamic banks from derived from the board/institution/takmir mosque of 55.I percent. While the account of sharia owned privately by 50 percent. It differs slightly from being managed using the name of the board/institution/takmir.
\end{abstract}

Keywords: Understanding of Bank Syariah, Islamic Bank Account, Mosque Management

\begin{abstract}
Abstrak
Penelitian ini merupakan penelitian kuantatif yang menggunakan metode deskriptif analitis. Dalam hal ini dengan cara mendeskripsikan Analisis Determinasi Pemahaman Pemilihan Rekening Bank Syariah Pada Pengurus Masjid di DKI Jakarta. Rendahnya pemahaman pengurus Takmir Masjid akan pemahaman produk bank syariah apalagi kemanfaatan rekening bank syariah bagi perekonomian umat. Untuk itu perbankan syariah harus terus melakukan sosialisasi lebih gencar lagi lewat media yang lebih populer di pengurus Takmir Masjid. Hasil penelitian menyimpulkan bahwa kepemilikan rekening dalam bank syariah dari berasal dari pengurus/lembaga/takmir masjid sebesar 55, I persen. Sedangkan rekening syariah yang dimiliki pribadi sebesar 50 persen. Berbeda sedikit dengan yang dikelola dengan menggunakan nama pengurus/lembaga/takmir.
\end{abstract}

Kata Kunci: Pemahaman Bank Syariah, Rekening Bank Syariah, Pengurus Masjid 


\section{A. PENDAHULUAN}

Dalam sepuluh tahun terakhir, industri keuangan syariah di Indonesia, yang didominasi oleh perbankan syariah, mengalami pertumbuhan signifikan dengan kecepatan rata-rata 30-40 persen, kecuali dua tahun terakhir yang mengalami perlambatan pertumbuhan disebabkan kondisi ekonomi yang tidak stabil. Namun sayangnya, apabila dilihat rata-rata pangsa pasar keuangan syariah masih belum menggembirakan karena masih di bawah lima persen. Hal ini mestinya menjadi pertanyaan besar dan tantangan tersendiri karena tidak berbanding lurus dengan potensi besar yang dimiliki. Sebagai negara dengan populasi Muslim terbesar di dunia, mestinya Indonesia bisa menjadi pemain utama (key player) dalam keuangan syariah. Keuangan syariah bisa tumbuh besar dan mendunia karena masih banyak potensi yang belum tersentuh (untapped resources). Berkembangnya keuangan syariah juga akan memberikan kontribusi positif dalam memperkuat perekonomian negara (Abdul Rasyid: 2016).

Baru-baru ini di Jakarta, tanggal II Maret 2016, Islamic Research and Training Institute-Islamic Development Bank (IRTI-IDB), Thomson Reutures, dan General Council for Islamic Banks and Financial Institutions (CIBAFI) meluncurkan Islamic Finance Report Country Report for Indonesia dengan thema 'Prospect for Exponential Growth'. Report ini didesain bagi menyediakan analisis secara rinci dan wawasan utama pengembangan keuangan syariah di Indonesia serta potensi besar perkembangan yang bisa ditawarkan oleh negara. Report ini menghighlight bagaimana Indonesia, sebagai negara besar dengan mayoritas Muslim hampir $85 \%$ dari 237.6 juta orang total penduduk sesuai catatan BPS tahun 2010, memiliki sumber daya alam yang melimpah dan lokasi geografis yang strategis, menawarkan potensi besar dalam pertumbuhan ekonomi dan berbagai peluang bagi industri keuangan syariah.

Berbeda dengan negara-negara lain, industri keuangan syariah di Indonesia sebagian besar dibangun atas inisiatif masyarakat (community based initiatives). Dengan kata lain, inisiasi pertumbuhan keuangan syariah di Indonesia dilakukan melalui bottom-up approach bukan top-down approach. Keinginan tersebut muncul dari masyarakat lalu diakomodasi oleh pemerintah, bukan sebaliknya. Namun, setidak-tidaknya hal tersebut membawa kesan positif dengan memunculkan berbagai pengembangan fitur unik seperti kehadiran BPR syariah, sukuk ritel, dana haji dan berbagai inisiatif keuangan sosial yang inovatif lainnya.

Keuangan syariah akhir ini bisa kita jumpai pada pemenuhan kebutuhan pengurus masjid di DKI Jakarta. Tidak sedikit pengetahuan pengurus akan pentingnya penggunaan rekening bank syariah. Lasana yang paling mutakhir dari 
kurang pemahaman akan pentingnya pemakaian rekening bank syariah karena minimnya sosialisasi yang telah dilakukan bank syariah maupun upaya yang dilakukan oleh Bank Indonesia. Menurut laporan akhir tahun Bank Indonesia 2006, kegiatan sosialisasi oleh Bank Indonesia sepanjang tahun 2006 hanyalah 5I kali. Hal itu tidak jauh berbeda dengan tahun 2007. Sebuah upaya yang sangat minim mengingat besarnya jumlah penduduk Indonesia. Idealnya dalam setahun bisa dilakukan minimal 5 juta kali sosialisasi dalam setahun, bukan 5I kali. Oleh karena, program sosialisasi perlu dilaksanakan lebih ekstra di tahun 2008, baik oleh bank Indonesia, bank-bank syariah, akademisi dan masyarakat ekonomi syariah secara umum.

Bentuk sosialisasi perbankan syariah sangat beragam dan luas, seperti melalui media massa cetak atau elektronik, kegiatan pameran, buletin, majalah, buku, lembaga pendidikan, dan sebagainya.

Masih banyak orang awam yang beranggapan bahwa menabung di bank syariahsama saja dengan dengan menabung di bank konvensional. Persepsi umum ini masih menghinggapi masyarakat, sehingga tidak heran mereka masih enggan untuk menjadi nasabah dan mendapatkan pembiayaan dari perbankan syariah. Hal ini bisa dilihat darilambannya pertumbuhan perbankan syariah, kendati potensinya sangat besar mengingatsebagian penduduk Indonesia beragama islam. Data membuktikan, bahwa market share perbankan syariah saat ini per Juli 2010 ini mencapai 2,78\% diprediksi sampaiakhir tahun bisa mencapai 3\% dari total asset perbankan secara nasional. Angka ini menunjukkan masih kecilnya kontribusi perbankan syariah terhadap perekonomian Indonesia.

Market share perbankan syariah yang masih rendah disebabkan karena program sosialisasi yang dilakukan belum optimal. Hal itu akibat masih sulitnya merubah pola pikir masyarakat untuk memilih bank syariah. Hingga kini masyarakat, masih terbiasa dengan bank konvensional, dibandingkan bank syariah. Artinya, sosialisasi perbankan syariah masih sangat kurang. Masyarakat luas di berbagai segmen masih belum banyak mengerti sistem, konsep, filosofi, produk, keuntungan dan keunggulan bank syariah. Setidaknya ada dua masalah penting dalam perbankan syariah dan dipersepsikan salah oleh masyarakat awam. Pertama, mengenai benchmark pembiayaan dan bagi hasil dengan tingkat suku bunga (interest rate) yang berlaku umum (di Indonesia misalnya BIrate atau LIBOR di level internasional).

Masalah kedua adalah pembiayaan pada perbankan syariah yang dipersepsikan hanya menganut prinsip bagi hasil. Benchmark adalah hal yang umum 
di praktekkan dalam dunia bisnis termasuk perbankan. Benchmark adalah studi untuk membandingkan kinerja aktual dengan standar kompentensi atau suatu standar untuk basis perbandingan. Prof. Dr. MA. Mannan, pakar ekonomi Islam, dalam buku Ekonomi Islam, sejak tahun 1970 telah mengingatkan pentingnya upaya edukasi masyarakat tentang keunggulan sistem syariah dan keburukan dampak sistem ribawi. Dalam hal ini keseriusan Bank Indonesia perlu dipertanyakan, karena selama ini Bank Indonesia tidak memberikan perhatian yang berarti bagi upaya sosialisasi bank syariah, karena hanya sosilisasi sebanyak 5I kali dalam setahun. Betul, Bank Indonesia telah mendorong secara signifikan dari aspek regulasi seperti office channeling dan peraturan lainnya yang mendukung berkembangnya perbankan syariah.

Namun dari segi edukasi yang meluas, masih jauh panggang dari api.

Harus diakui bahwa hampir satu juta masjid dan mushalla di Indonesia, sepi dari dakwah ekonomi syariah, padahal di situ berkumpul puluhan bahkan seratusan juta umat Islam, khususnya pada momentum khutbah jumat. Kesalahan besar Bank Indonesia atau juga bank-bank syariah ialah mereka mengatakan bahwa pasar tersebut bersifat segmented dan sudah jenuh, sehingga market share masih I.7 \% (baca Outlook Perbankan syariah 2008, hal, I5). Justru ceruk pasar jamaah masjid itulah yang masih terbuka luas yang belum digarap bank-bank syariah dan belum diperhatikan Bank Indonesia. Pasar inilah yang harus menjadi perioritas.

Di masjid berkumpul para pengusaha, hartawan, para presiden direktur, pejabat penting, tokoh masyarakat dan sebagainya. Jangan dianggap jamaah yang shalat jumat di masjid-masjid adalah masyarakat biasa atau tukang ojek. Tidak. Sekali-kali tidak. Ceruk pasar lainnya adalah masjid ta'lim, kelompok bimbingan jamaah haji, pesantren dan sebagainya.

5 juta kali sosialisasi sebagaimana disebut di atas, bahwa idealnya sosialisasi perbankan syariah dilakukan sebanyak 5 juta kali dalam setahun. Asumsinya, jumlah masjid di Indonesia sekitar 600.000 buah. Jika dalam setahun hanya I kali sosialisasi di tiap masjid, maka dibutuhkan 600.000 kali sosialisasi. Ingat di masjidmasid tidak cukup hanya sekali sosialisasi, minal 3 atau 4 kali sosialisasi, agar pemahaman jamaah benar-benar mendalam, bukan sekedar kulit. Maka jika di setiap masjid hanya dilakukan 4 kali sosialisasi, maka dibutuhkan 2,4 juta kali sosialisasi. Belum termasuk sosialisasi terhadap 600.000 ustaz/ulamanya sebagai guru ekonomi syariah yang akan menyampaikan dakwah ekonomi Islam. Untuk mentraining para ulama minimal dibutuhkan 6.000 kali sosialisasi, dengan asumsi setiap sosialiasi dihadiri 100 peserta dan setiap sosialisasi memakan waktu 3 hari. 
Sosialisasi juga mutlak dilakukan berkali-kali dalam setahun kepada majlis ta'lim ibu-ibu yang tersebar di seluruh Indonesia. Ingat, hampir di setiap desa dan kelurahan terdapat majlis ta'lim ibu-ibu, jumlahnya ratusan ribu majlis ta'lim ibuibu. Jika sosialisasi keada majlis ta'lim ibu dilakukan hanya 4 kali, maka paling tidak dibutuhkan 3.000.000 kali sosialisasi dengan asumsi di Indonesia ada 750 ribu kelompok majlis ta'lim.

Dengan masih rendahnya pemahaman takmir masjid akan produk bank syariah apalagi penggunaan rekening bank syariah bagi perekonomian umat lebih luas maka perbankan syariah harus terus berkembang dan memperbaiki kinerjanya. Dengan pesatnya pertumbuhan yang ditandai semakin banyaknya bank konvensional yang akhirnya mendirikan unit-unit syariah, ini membuktikan bahwa bank syariah memang mempunyai kompetensi yang tinggi. Perbankan syariah akan semakin tinggi lagi pertumbuhannya apabila masyarakat mempunyai permintaan dan antusias yang tinggi dikarenakan faktor peningkatan pemahaman dan pengetahuan tentang bank syariah, disamping faktor penyebab lainnya Oleh karena itu, tema yang akan diambil adalah analisis pemahaman pemilihan rekening bank syariah pada pengurus masjid di DKI Jakarta.

\section{B. METODE}

Penelitian ini merupakan penelitian kuantatif yang menggunakan metode deskriptif analitis. Dalam hal ini dengan cara mendeskripsikan Analisis Determinasi Pemahaman Pemilihan Rekening Bank Syariah Pada Pengurus Masjid di DKI Jakarta. Penelitian kuantitatif digunakan untuk meneliti pada populasi atau sampel tertentu. Teknik pengambilan sampel pada umumnya dilakukan secara random, pengumpulan data menggunakan instrument penelitian, analisis data bersifat kuantitatif/statistik dengan tujuan untuk menguji hipotesis yang telah ditetapkan (Sugiyono, 2012:7).

Pemilihan sampel penelitian dilakukan dengan menggunakan metode purposive sample (judgment sample), yaitu cara pengambilan sampel yang dilakukan dengan membuat kriteria-kriteria (penilaian) untuk memenuhi tujuan. Kriteria yang ditetapkan didasarkan pada informasi yang tersedia, sehinga perwakilannya terhadap populasi dapat dipertanggungjawabkan (Sarwono, 2006:138).

Berdasarkan pemahaman tersebut, maka proses penelitian dilakukan sesuai langkah-langkah sebagai berikut: Pengambilan sample dilakukan secara purposive random sampling yang dilakukan oleh peneliti. Dimana diketahui secara pasti 
jumlah populasinya sehingga peneliti menentukan jumlah sampel yang akan diteliti dan memenuhi kuota dari jumlah sampel yang diinginkan oleh peneliti. Sehingga dipilihlah sebanyak 49 responden yang digunakan sebagai sampel yang dirasa cukup mewakili pengurus masjid dengan kualifikasi yang tersebar di DKI Jakarta dengan persentase Jakarta Barat, Jakarta Timur, Jakarta Selatan, Jakarta Pusat, dan Jakarta Utara. Teknik analisis data mengggunakan analisis logit regresi.

\section{HASIL DAN PEMBAHASAN}

Penelitian ini merupakan penelitian kuantatif yang menggunakan metode deskriptif analitis. Dalam hal ini dengan cara mendeskripsikan Analisis Determinasi Pemahaman Pemilihan Rekening Bank Syariah Pada Pengurus Masjid di DKI Jakarta. Pengambilan sample dilakukan secara purposive random sampling yang dilakukan oleh peneliti. Dimana diketahui secara pasti jumlah populasinya sehingga peneliti menentukan jumlah sampel yang akan diteliti dan memenuhi kuota dari jumlah sampel yang diinginkan oleh peneliti. Sehingga dipilihlah sebanyak 49 responden yang digunakan sebagai sampel yang dirasa cukup mewakili pengurus masjid dengan kualifikasi yang tersebar di DKI Jakarta dengan persentase Jakarta Barat, Jakarta Timur, Jakarta Selatan, Jakarta Pusat, dan Jakarta Utara. Teknik analisis data mengggunakan analisis logit regresi. Pengukuran kuesioner untuk variable bebas mengunakan skala ordinal dan rasio.

\section{Hasil}

\section{Tabel.I}

\section{Kepemilikan Rekening dalam Bank Syariah}

\begin{tabular}{ll|r|r|r} 
& $\begin{array}{c}\text { Frequenc } \\
\text { y }\end{array}$ & Percent & $\begin{array}{c}\text { Valid } \\
\text { Percent }\end{array}$ & \multicolumn{1}{c}{$\begin{array}{c}\text { Cumulative } \\
\text { Percent }\end{array}$} \\
\hline Valid Pribadi & 22 & 44,9 & 44,9 & 44,9 \\
\hline $\begin{array}{l}\text { pengurus/lembaga/ta } \\
\text { kmir masjid }\end{array}$ & 27 & $55, \mathrm{I}$ & $55, \mathrm{I}$ & $\mathrm{I00,0}$ \\
\hline \begin{tabular}{l} 
Total \\
\hline
\end{tabular} & 49 & $\mathrm{I00,0}$ & $\mathrm{I00,0}$ & \\
\hline
\end{tabular}

Sumber : Hasil Pengolahan Data Penelitian, 2017 
Dari data diatas, dapat disimpulkan bahwa kepemilikan rekening dalam bank syariah dari seluruh responden, berasal dari pengurus/lembaga/takmir masjid, sebesar 55,I \%. Sedangkan rekening syariah yang dimiliki pribadi sebesar 50 persen. Jdi ada perbedaan sedikit dengan yang dikeloa dengan menggunakan nama pengurus/lembaga/takmir.

\section{Tabel.2}

\section{Status Kepemilikan Masjid}

\begin{tabular}{rl|r|r|r} 
& $\begin{array}{c}\text { Frequenc } \\
\text { y }\end{array}$ & Percent & & $\begin{array}{c}\text { Cumulative } \\
\text { Percent }\end{array}$ \\
\hline Valid & $\mathrm{I}$ & 2,0 & 2,0 & 2,0 \\
\hline \begin{tabular}{r|r|r|r|r} 
Negara \\
Ormas
\end{tabular} & 2 & $4, \mathrm{I}$ & $4, \mathrm{I}$ & $6, \mathrm{I}$ \\
\hline Pemda & 3 & $6, \mathrm{I}$ & $6, \mathrm{I}$ & $\mathrm{I} 2,2$ \\
\hline Yayasan & $\mathrm{I}$ & 2,0 & 2,0 & $\mathrm{I} 4,3$ \\
\hline Pribadi & $\mathrm{I}$ & 2,0 & 2,0 & $\mathrm{I} 6,3$ \\
\hline Umum & $\mathrm{I}$ & 2,0 & 2,0 & $\mathrm{I}, 4$ \\
\hline Wakaf & 40 & $8 \mathrm{I}, 6$ & $8 \mathrm{I}, 6$ & $\mathrm{I}, 6$ \\
\hline Total & 49 & $\mathrm{I} 00,0$ & $\mathrm{I}, 0$ & \\
\hline
\end{tabular}

Sumber : Hasil Pengolahan Data Penelitian, 2017

Berdasarkan pengolahan data diatas, dapat disimpulkan bahwa status kepemilikan dari 49 masjid yang menjadi responden, 82\% merupakan masjid dengan status kepemilikan yakni wakaf yang memiliki valid percent tertinggi. Sedangkan masjid dengan kepemilikan negara, umum, pribadi, dan yayasan persentasenya sebesar $2 \%$. Sedangkan masjid yang dimiliki ormas sebesar 4,I persen dan pemda sebesar 6,I persen. 


\section{Tabel.3}

\section{Dari Mana Bapak/Ibu mendapatkan Informasi tentang Bank Syariah}

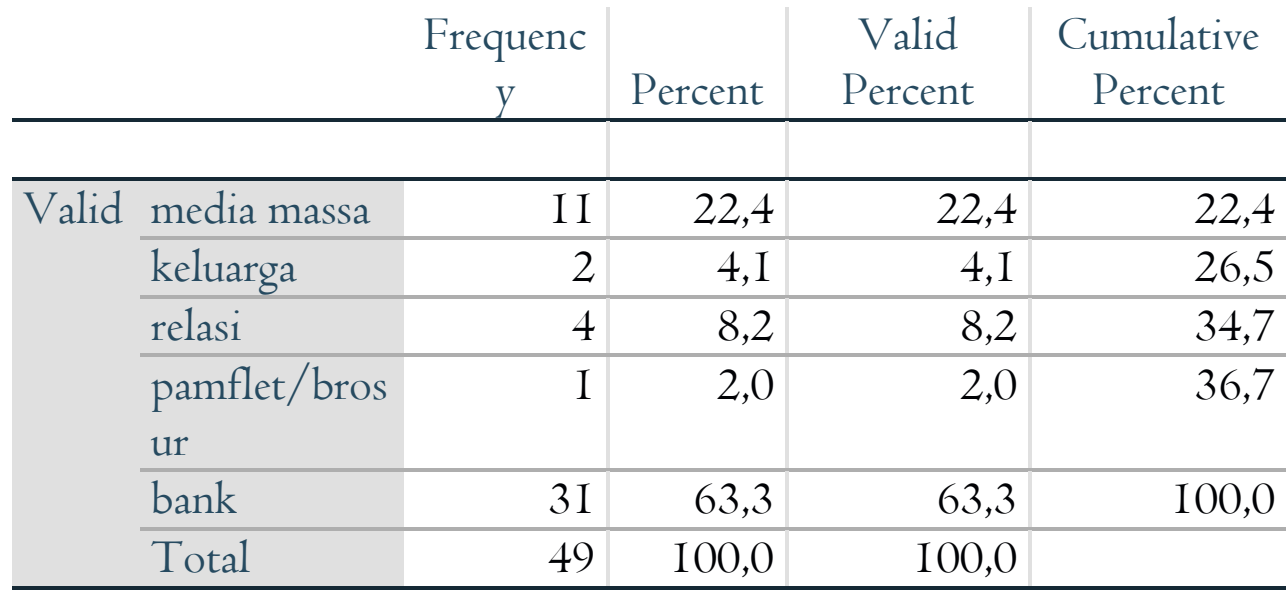

Sumber : Hasil Pengolahan Data Penelitian, 2017

Data diatas menunjukkan bahwa bapak/ibu responden mendapatkan informasi tentang bank syariah paling banyak melalui bank syariah itu sendiri, yakni sebesar 63\%. Selain itu yang mendapatkan informasi dari media massa sebesar 22,4 persen. Sedangkan dari keluarga sebesar 4,I \%. Kemudian relasi sahabat sebesar 8,2 $\%$ dan dari pamplet sebesar 2,0 \%.

\section{Tabel.4}

\section{Apa yang menjadi alasan Takmir Masjid memilih Bank Syariah}

\begin{tabular}{|c|c|c|c|c|c|}
\hline & & $\begin{array}{c}\text { Frequenc } \\
\mathrm{y}\end{array}$ & Percent & $\begin{array}{l}\text { Valid } \\
\text { Percent }\end{array}$ & $\begin{array}{l}\text { Cumulative } \\
\text { Percent }\end{array}$ \\
\hline Valid & $\begin{array}{l}\text { sekedar ikut-ikutan } \\
\text { nasabah lain }\end{array}$ & 6 & $\mathrm{I} 2,2$ & $\mathrm{I} 2,2$ & $\mathrm{I} 2,2$ \\
\hline & lokasi yang strategis & 2 & $4, \mathrm{I}$ & $4, \mathrm{I}$ & 16,3 \\
\hline & $\begin{array}{l}\text { mudahnya persyaratan } \\
\text { menjadi nasabah bank } \\
\text { syariah }\end{array}$ & I7 & 34,7 & 34,7 & $5 \mathrm{I}, 0$ \\
\hline & $\begin{array}{l}\text { menggunakan sistem } \\
\text { bagi hasil }\end{array}$ & 24 & 49,0 & 49,0 & IOO,0 \\
\hline & Total & 49 & 100,0 & 100,0 & \\
\hline
\end{tabular}

Sumber : Hasil Pengolahan Data Penelitian, 2017. 
Dari data diatas menunjukkan alasan terbanyak yang dipilih responden dalam memilih bank syariah adalah karena di bank syariah menganut sistem bagi hasil, sebesar $49 \%$. Selain itu yang mendapatkan informasi dari sekedar ikut-ikutan nasabah lain sebesar I2,2 persen. Sedangkan dari lokasi yang strategis sebesar 4,I\%. Kemudian mudahnya persyaratan menjadi nasabah bank syariah sebesar 34,7 $\%$ dan dari menggunakan sistem bagi hasil sebesar 49,0 \%.

\section{Tabel.5.}

\section{Sudah berapa lama Masjid ini menjadi Nasabah Bank Syariah}

\begin{tabular}{l|r|r|r|r} 
& $\begin{array}{c}\text { Frequenc } \\
\text { y }\end{array}$ & Percent & $\begin{array}{c}\text { Valid } \\
\text { Percent }\end{array}$ & $\begin{array}{c}\text { Cumulative } \\
\text { Percent }\end{array}$ \\
\hline $\begin{array}{l}\text { Valid di bawah I } \\
\begin{array}{l}\text { tahun } \\
\text { I-2 tahun }\end{array}\end{array}$ & $4, \mathrm{I}$ & $4, \mathrm{I}$ & $4, \mathrm{I}$ \\
\hline 2-3 tahun & 3 & $6, \mathrm{I}$ & $6, \mathrm{I}$ & $\mathrm{I}$ \\
\hline diatas 3 tahun & $\mathrm{I} 7$ & 34,7 & 34,7 & 44,9 \\
\hline Total & 27 & $55, \mathrm{I}$ & $55, \mathrm{I}$ & $\mathrm{I00,0}$ \\
\hline
\end{tabular}

Sumber: Hasil Pengolahan Data Penelitian, 2017.

Data diatas menunjukkan bahwa 55\% responden telah menjadi nasabah bank syariah selama lebih dari 3 tahun. Selain itu yang mendapatkan informasi dari dibawah I tahun sebesar 4,I persen. Sedangkan dari I-2 tahun sebesar 6,I \%. Kemudian 2-3 tahun sebesar 34,7\% dan dari diatas 3 tahun sebesar 55,I \%.

\section{Tabel.6}

Biasanya berapa kali dalam sebulan bapakibu sebagai pengurus Masjid bertransaksi di Bank Syariah

\begin{tabular}{|c|c|c|c|c|c|}
\hline & & $\begin{array}{c}\text { Frequenc } \\
y\end{array}$ & Percent & $\begin{array}{l}\text { Valid } \\
\text { Percent }\end{array}$ & $\begin{array}{c}\text { Cumulative } \\
\text { Percent }\end{array}$ \\
\hline \multirow{5}{*}{ Valid } & I kali & 2 & $4, \mathrm{I}$ & $4, \mathrm{I}$ & $4, \mathrm{I}$ \\
\hline & 2 kali & 5 & $\mathrm{I0,2}$ & $\mathrm{I} 0,2$ & $\mathrm{I} 4,3$ \\
\hline & 3 kali & I7 & 34,7 & 34,7 & 49,0 \\
\hline & $\begin{array}{l}>3 \\
\text { kali }\end{array}$ & 25 & $5 \mathrm{I}, 0$ & $5 \mathrm{I}, 0$ & I00,0 \\
\hline & Total & 49 & I00,0 & $\mathrm{I} 00,0$ & \\
\hline
\end{tabular}

Sumber: Hasil Pengolahan Data Penelitian, 2017. 
Data diatas menunjukkan bahwa 5I\% responden melakukan transaksi di bank syariah dalam I bulan adalah lebih dari 3 kali. Selain itu yang mendapatkan informasi dari dibawah I kali sebesar 4, I persen. Kemudian 2 kali sebesar 10,2 \% dan dari diatas 3 kali sebesar 34,7\% dan dari $>3$ kali sebesar 5 I,0\%.

\section{Tabel. 7.}

Apakah produk yang bapak/ibu gunakan pada Bank Syariah

\begin{tabular}{|c|c|c|c|c|c|}
\hline & & Frequency & Percent & $\begin{array}{l}\text { Valid } \\
\text { Percent }\end{array}$ & $\begin{array}{l}\text { Cumulativ } \\
\text { e Percent }\end{array}$ \\
\hline \multirow[t]{4}{*}{ Valid } & & 25 & $5 \mathrm{I}, 0$ & $5 \mathrm{I}, 0$ & $5 \mathrm{I}, 0$ \\
\hline & tabungan mudharabah & 16 & 32,7 & 32,7 & 83,7 \\
\hline & tabungan wadiah & 8 & 16,3 & 16,3 & $\mathrm{I} 00,0$ \\
\hline & Total & 49 & 100,0 & 100,0 & \\
\hline
\end{tabular}

Sumber: Hasil Pengolahan Data Penelitian, 2017.

Data diatas menunjukkan bahwa 33\% produk yang banyak digunakan oleh reponden pada bank syariah adalah tabungan mudharabah. Selain itu yang mendapatkan informasi dari tabungan mudharabah kali sebesar 32,7 persen. Kemudian tabungan wadiah sebesar $16,3 \%$.

\section{PEMBAHASAN}

Dengan masih rendahnya pemahaman takmir masjid akan produk bank syariah apalagi penggunaan rekening bank syariah bagi perekonomian umat lebih luas maka perbankan syariah harus terus berkembang dan memperbaiki kinerjanya. Dengan pesatnya pertumbuhan yang ditandai semakin banyaknya bank konvensional yang akhirnya mendirikan unit-unit syariah, ini membuktikan bahwa bank syariah memang mempunyai kompetensi yang tinggi. Perbankan syariah akan semakin tinggi lagi pertumbuhannya apabila masyarakat mempunyai permintaan dan antusias yang tinggi dikarenakan faktor peningkatan pemahaman dan pengetahuan tentang bank syariah, disamping faktor penyebab lainnya.

Menurut Ayub, Moh. E. dkk. (1996) dalam Manajemen Masjid. Peran dan tugas takmir tidak tidak hanya terbatas urusan ibadah masyarakat, tetapi menyangkut kesejahteraan duniawi umat. Secara spesifik, dijelaskan bahwa selama ini masjid belum banyak mengetahui perbankan dan keuangan syariah, padahal entitas ini sangat penting dalam meningkatkan kesejahteraan masyarakat. Sehingga perlu ada sinergi dan upaya-upaya agar masjid melalui takmirnya mengetahui, 
mendukung, dan mempunyai program mensejahterakan jama'ah melelaui entitas perbankan dan keuangan syariah

\section{SIMPULAN}

Rendahnya pemahaman pengurus Takmir Masjid akan pemahaman produk bank syariah apalagi kemanfaatan rekening bank syariah bagi perekonomian umat. Untuk itu perbankan syariah harus terus melakukan sosialisasi lebih gencar lagi lewat media yang lebih populer di pengurus Takmir Masjid. Kepemilikan rekening dalam bank syariah dari seluruh responden, berasal dari pengurus/lembaga/takmir masjid, sebesar 55,I \%. Sedangkan rekening syariah yang dimiliki pribadi sebesar 50 persen. Jadi ada perbedaan sedikit dengan yang dikelola dengan menggunakan nama pengurus/lembaga/takmir.

Pengurus Takmir masjid memilih bank syariah adalah karena di bank syariah menganut sistem bagi hasil, sebesar 49\%. Selain itu yang mendapatkan informasi dari sekedar ikut-ikutan nasabah lain sebesar I2,2 persen. Sedangkan dari lokasi yang strategis sebesar 4,I \%. Kemudian mudahnya persyaratan menjadi nasabah bank syariah sebesar 34,7 \% dan dari menggunakan sistem bagi hasil sebesar 49,0 \%. responden telah menjadi nasabah bank syariah selama lebih dari 3 tahun. Selain itu yang mendapatkan informasi dari dibawah I tahun sebesar 4, I persen. Sedangkan dari I-2 tahun sebesar 6,I \%. Kemudian 2-3 tahun sebesar 34,7 \% dan dari diatas 3 tahun sebesar 55,I \%. \% produk yang banyak digunakan oleh reponden pada bank syariah adalah tabungan mudharabah. Selain itu yang mendapatkan informasi dari tabungan mudharabah kali sebesar 32,7 persen. Kemudian tabungan wadiah sebesar 16,3\% .

\section{PUSTAKA ACUAN}

Ayub, Moh. E. Dkk. (1996). Manajemen Masjid, Gema Insani Press: Jakarta. Ghozali, Imam. 2007. Aplikasi Analisis Multivariate Dengan Program SPSS. Cetakan IV. Badan Penerbit Universitas Diponegor: Semarang. 
Indriantoro, Nur dan Bambang Supomo. 2009. Metodologi Penelitian Bisnis Untuk Akuntansi dan Manajemen, Edisi Pertama. Balai Penerbitan Fakultas Ekonomi: Yogyakarta.

Islamic Banking Statistics, Bank Indonesia, 2009,

https://www.scribd.com/doc/76921094/Pengaruh-Sosialisasi-PerbankanSyariah-Terhadap-Preferensi-Masyarakat-Dalam-Memilih-Bank-Syariah diakses 26 Juli 2016.

Masyarakat Ekonomi Syariah. 20I3, Syariah Economic outlook, Jakarta

Panduan Pelaksanaan Penelitian di Perguruan Tinggi Edisi IX, Dirjen Dikti Kemendikbud 2013.

Rasyid, Abdul (2016). http://business-law.binus.ac.id/2016/03/3I/potensiperkembangan-keuangan-syariah-di-indonesia/ diakses Kamis, 2I Juli 2016,

Ratnawati, Anny. Dkk. (2016). Bank Syariah Potensi Preferensi \& Perilaku Masyarakat di Wilayah Jawa Barat, Jawa Barat: Lembaga Penelitian IPB.

Purnamasari, F., \& Darmawan, A. (2017). Islamic Banking and Empowerment of Small Medium Enterprise. ETIKONOMI, 16(2), 221-230.

Sugiyono, 2008, Metode Penelitian Kunatitatif Kualitatif dan R\&D, Bandung: Alfabeta.

Sarwono, Jonathan. (2006). Metode Penelitian Kuantitatif dan Kualitatif. Edisi Pertama. Cetakan Pertama, Yogyakarta: Graha Ilmu.

Syafí i, Antonio. (200I). Bank Syariah; dari Teori ke Praktek, Gema Insani Press: Jakarta 